\title{
A comparative study of finite element methodologies for the prediction of torsional response of bladed rotors
}

\author{
R. Scheepers ${ }^{1, *}$ and P.S. Heyns ${ }^{1}$ \\ ${ }^{1}$ Department of Mechanical and Aeronautical Engineering, University of Pretoria, Pretoria, South Africa \\ * Corresponding author. Tel.: +27 11629 5798, Fax.: +27 866674397 \\ E-mail address: ronnie.scheepers@eskom.co.za
}

\begin{abstract}
The prevention of torsional vibration-induced fatigue damage to turbo-generators requires determining natural frequencies by either field testing or mathematical modelling. Torsional excitation methods, measurement techniques and mathematical modelling are active fields of research. However, these aspects are mostly considered in isolation and often without experimental verification. The objective of this work is to compare one dimensional (1D), full three dimensional (3D) and 3D cyclic symmetric (3DCS) finite element (FE) methodologies for torsional vibration response. Results are compared to experimental results for a small-scale test rotor.

It is concluded that $3 \mathrm{D}$ approaches are feasible given the current computing technology and require less simplification with potentially increased accuracy. Accuracy of 1D models is reduced due to simplifications but faster solution times are obtained. For high levels of accuracy model updating using field test results is recommended.
\end{abstract}

Keywords: torsional vibration; Euler-Bernoulli; component mode synthesis; finite element; cyclic symmetric; torsional excitation.

\section{Introduction}

Increasing demand for electrical energy worldwide places pressure on turbo-generator designers and operators to deliver more power more cheaply. Expanding transmission systems utilize series capacitor compensation or high-voltage direct current systems which all increase the risk of torsional vibration induced fatigue damage $[1,2]$. Operators are required to ensure ever higher levels of reliability and availability in an environment where the reserve margins of installed capacity are decreasing, plant is aging and the opportunity for maintenance is limited. The Electric Power Research Institute (EPRI) reports twelve confirmed cases of torsional vibration induced fatigue failures between 1971 and 2004 [3]. These include failures of turbo-generator shafts, low-pressure turbine blades and coil retaining rings. Tsai [4] refers to low pressure turbine blade failures within one year of commissioning that were due to super-synchronous resonance.

The complexity of the models for describing these systems and to predict their vibrational response under various conditions has always relied heavily on the available computing power $[5,6]$. Although torsional vibration of turbo-generators has been identified and researched over many years, the accuracy of conventional models for the calculation of torsional vibration response remains unacceptable in some cases. Improved models need to be developed [7, 8], notably for supersynchronous resonance where blades may be affected. It has been concluded that the vibration response of blade-disk-shaft structures may be poorly modelled by conventional modelling techniques and by uncoupling the rotordynamic and bladed disk analyses [9].

Torsional excitation methods include the use of simple me- chanical devices, hydraulic as well as electrical drives. The use of an alternating-current motor coupled to a servo drive for the rotation and torsional excitation of small test rotors has been investigated previously [10]. The cogging torque of brushless direct-current (DC) motors has also been used for torsional excitation $[11,12]$. A DC motor and a digital control system for the rotation and torsional excitation of the test rotor were considered in the current work. The control system was optimized to ensure a fast transient and stable steady-state response. The vibration response of the drive system was characterized in order to consider its possible influence on the test rotor response and is discussed in Section 2.

Although analytical models still have value when investigating and understanding the principles of vibration response, it has been stated that the detailed 3D FE analysis of practical systems may offer the best approach to addressing real structures [13]. Due to the large number of degrees of freedom of 3D models, some form of simplification or reduction technique may be required to ensure practical solution times on the available computer systems. 3DCS analysis has been proposed as a solution [14]. 3D and 3DCS modelling are described in Sections 3 and 4.

1D torsional modelling requires simplification of the rotor geometry and other aspects. Although these simplifications result in models with fewer degrees of freedom which are readily solved with modern computers, they do tend to be less accurate. The features that require simplification and which could lead to inaccuracies include: participation of flexible low-pressure turbine blades in torsional modes, abrupt diameter changes, the complexity and speed-dependent stiffness of generators, shrunk on disks typically used in low-pressure 
turbines, the stiffness of bolted couplings and the effective stiffness of blade-to-disk mountings. The modelling technique applied in the current work is discussed in more detail in Section 5.

The objective of this work was to conduct a consistent, comparative study of the one-dimensional (1D), full threedimensional (3D) and three-dimensional cyclic symmetric (3DCS) finite element (FE) methodologies used for calculating the torsional vibration response of bladed rotors. The accuracy of these methodologies relative to the experimental results obtained for a small-scale test rotor was investigated. In addition, relative solution times were directly compared and considered against the increase (or decrease) in accuracy, preprocessing effort and expertise required.

The small-scale test rotor was designed so that it contains the basic elements of a real turbo-generator train. This includes at least three large inertias representing the highpressure and two low-pressure turbines. Long and flexible blades sized so that they participate in the higher-order torsional vibration modes were included. An electric machine, the DC motor, which has a complex construction with speed dependent vibration properties and which is influenced by electro-magnetic forces is representative of a generator. Sudden diameter changes from shaft sections to disks and couplings as well as the effect of shrunk-on discs as found in turbo-generator trains were also included. In order to demonstrate the effect of the degree of blade mode participation in shaft torsional vibration modes, the effective torsional stiffness of the blades can be changed by varying the stagger angle of the blades.

\section{Experimental setup and modal testing}

\subsection{Test rotor design and drive system characterization}

A test rotor was designed and built for laboratory testing and measurement, consisting of a shaft, three disks, eight blade holders with blades, a drive end (DE) coupling and a DC motor. Blades can be fitted in the $0^{\circ}, 45^{\circ}$ or $90^{\circ}$ position, known as the blade stagger angle, where $90^{\circ}$ is the position with the blade width aligned in the tangential direction (or perpendicular to the shaft centre line) as shown in Fig. 1. Rotational drive and torsional excitation were accomplished

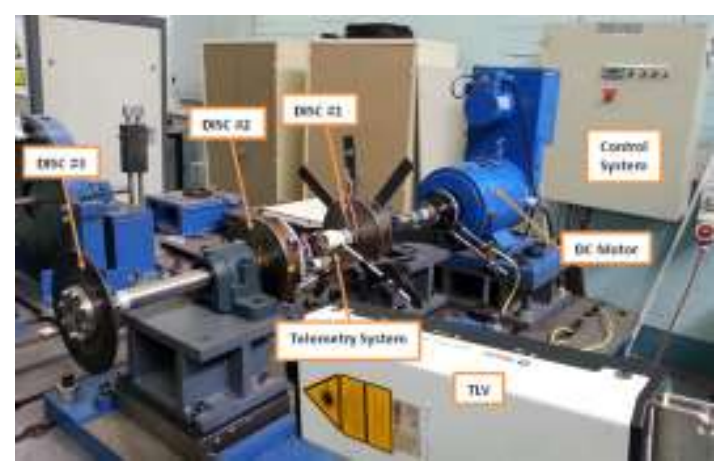

Fig. 1. Test rotor with blades at a $90^{\circ}$ stagger angle. through a drive system consisting of a $3 \mathrm{~kW}$ DC motor and a digital control system which allows for fully reversible operation i.e. the motor can act to drive or brake the test rotor. The rotor was coupled to the DC motor with a flanged coupling and was supported by two self-aligning roller element bearings. Based on the initial performance tests, a decision was taken to use speed control instead of torque control, as this provides a faster transient response as well as a more stable constant speed operation. Speed feedback based on armature voltage was used. A typical speed step response is shown in

Fig. 2. A $\pm 10 \mathrm{~V}$ signal (iOut) proportional to the armature current was available from the control system as an output. A rotary shaft encoder was attached to the NDE side of the motor, and has a resolution of 1000 pulses per revolution. It was used to generate an analogue $\pm 10 \mathrm{~V}$ speed signal which is equivalent to $\pm 3000 \mathrm{rpm}$ (nOut).

The polar moment of inertia of the motor armature was determined experimentally by using the torsional pendulum approach and a torsional laser vibrometer (TLV) as $7.8 \mathrm{mg} \cdot \mathrm{m}^{2}$.

Using the control signal as reference and the speed response measured using the TLV, the frequency response functions (FRFs) for sudden speed steps of $250 \mathrm{rpm}$ from various mean speeds were calculated. A control system natural frequency was detected at $2.5 \mathrm{~Hz}$, which does not change with rotational speed (Fig. 3).
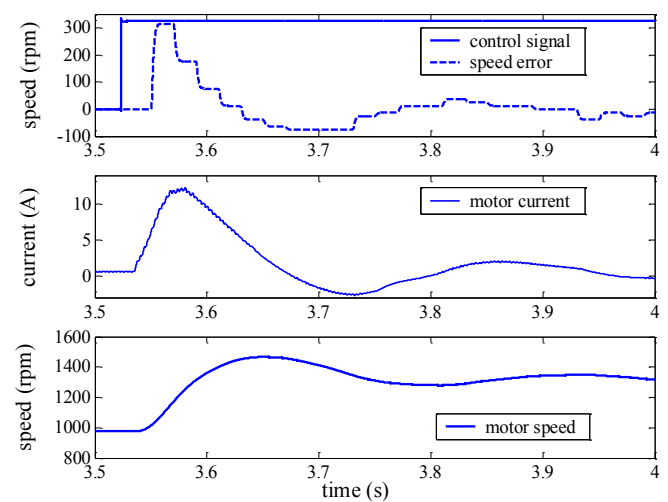

Fig. 2. Response of optimized drive system to a speed step change. 


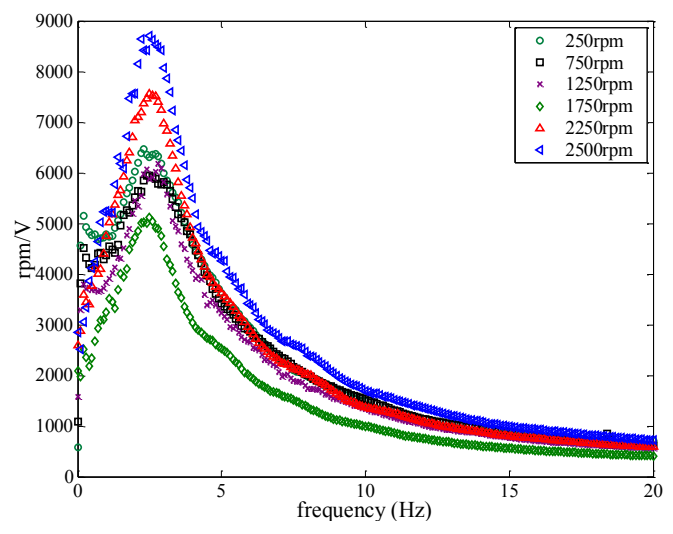

Fig. 3. Frequency response magnitude of drive system for various rotational speeds.

An average drive system damping coefficient of 0.90 N.s/deg was calculated, using the half-power method. Damping was also calculated using the log decrement method and found to be approximately $0.95 \mathrm{~N}$.s/deg. No significant change in damping with speed was noted, although the calculated values at speeds $>1000 \mathrm{rpm}$ were more consistent.

To determine the typical background noise generated by the motor and control system, Fast Fourier Transforms (FFTs) of nOut and IOut (Fig. 4) were calculated with the motor running freely. Frequency content was detected at multiples of running speed and line frequency as well as at $300 \mathrm{~Hz}$ and multiples thereof. Similar frequency content was also seen in the FFTs of the speed signal. This proved to be problematic as one torsional mode was found to be close to $300 \mathrm{~Hz}$, depending on the blade stagger angle.

\subsection{Static modal testing of the test rotor}

Two full Wheatstone bridges and a $1 \mathrm{kHz}$ bandwidth telemetry system were used for measuring the torque and bending strain of the shaft and blade \#1. Strain gauge pairs were applied in-board of disk \#2 on the rotor shaft and just above the blade \#1 holder (Fig. 5).

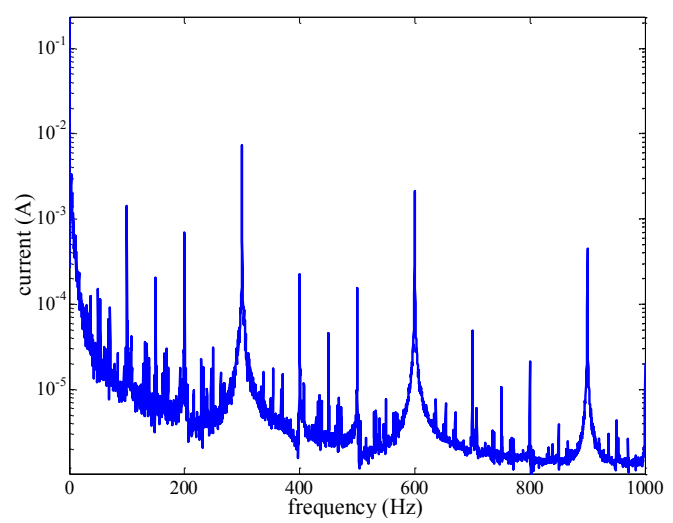

Fig. 4. FFT of motor current signal with motor running freely.

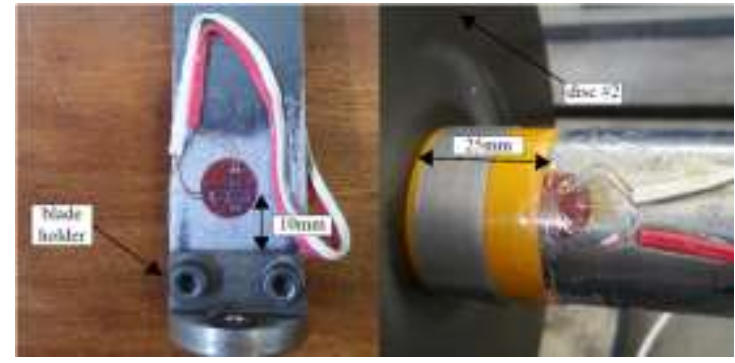

Fig. 5. Strain gauges used to measure blade bending (left) and shaft torsional (right) response.

Modal tests of the rotor were conducted with blades in the $0^{\circ}$, $45^{\circ}$ and $90^{\circ}$ positions as well as with no blades, using the TLV to measure angular speed response. Excitation was accomplished by tangential impacts on a nut mounted on the DE coupling (at a diameter of $59 \mathrm{~mm}$ ) using an instrumented impact hammer. The linear vibration response of the rotor was confirmed by identifying reciprocity in the response of the DE coupling/disk \#3 impact and measurement position pair (Fig. 6). Five torsional modes were measured but only the latter four (referenced as F1 to F4) are reported here as the first mode was not detected for the dynamic case (see Table 1). Frequencies of modes F1 and F3 are affected by the blade stagger angle whereas modes F2 and F4 are not affected.
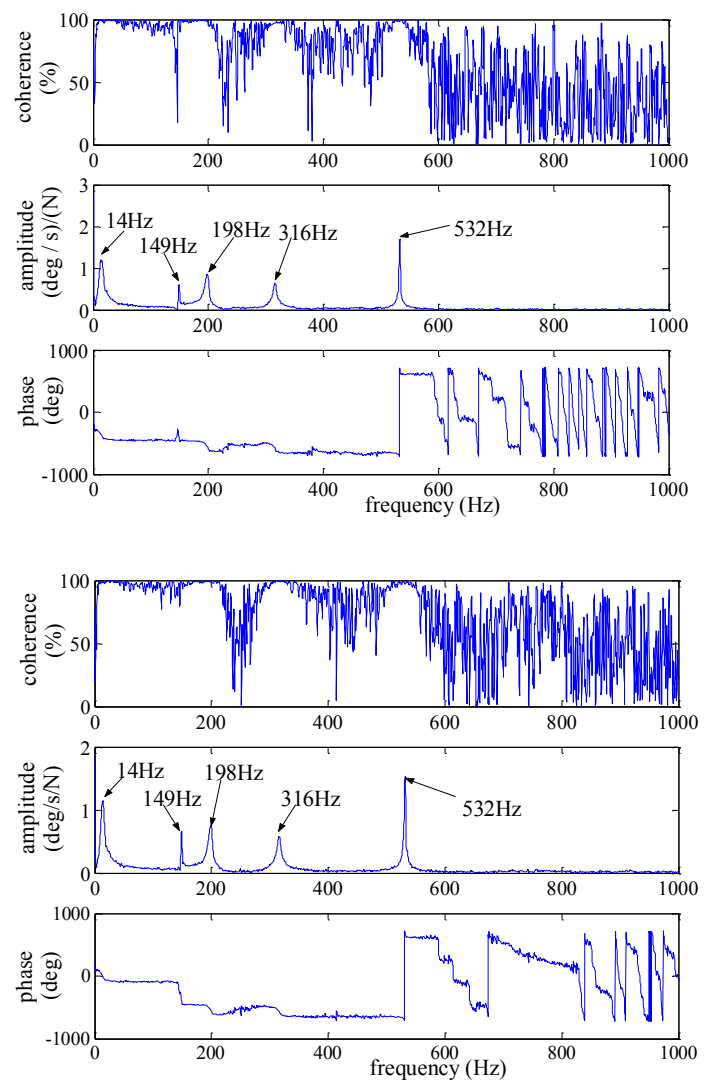

Fig. 6. Reciprocity shown for shaft torsional response shown for impact $\mathrm{DE} /$ measure disk \#3 (top) and impact disk \#3/measure DE (bottom). 
Table 1. Summary of measured static torsional frequencies.

\begin{tabular}{c|c|c|c|c}
\hline $\begin{array}{c}\text { Blade } \\
\text { stagger angle }\end{array}$ & $F_{1}(\mathrm{~Hz})$ & $F_{2}(\mathrm{~Hz})$ & $F_{3}(\mathrm{~Hz})$ & $F_{4}(\mathrm{~Hz})$ \\
\hline no blades & & 200 & 351 & 534 \\
\hline $0^{\circ}$ & 152 & 198 & 336 & 534 \\
\hline $45^{\circ}$ & 149 & 199 & 315 & 533 \\
\hline $90^{\circ}$ & & 199 & 303 & 533 \\
\hline
\end{tabular}

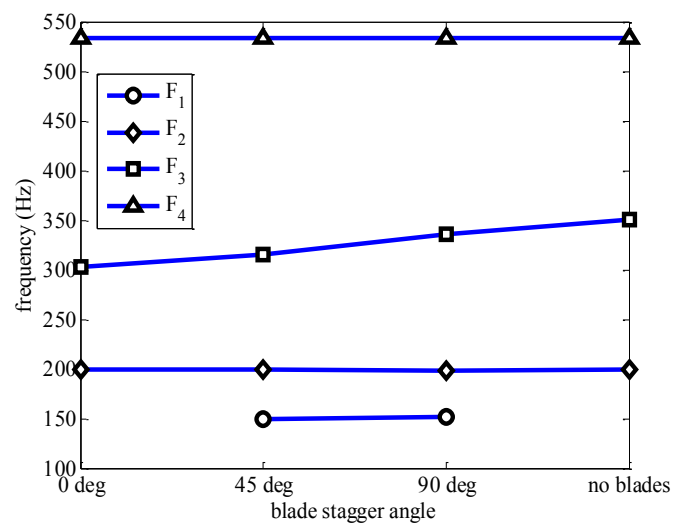

Fig. 7. Variation of torsional frequencies with blade stagger angle.

\subsection{Dynamic modal testing}

A random noise signal with a bandwidth of $1 \mathrm{kHz}$ and a peak level of $100 \mathrm{mV}$ was generated and connected to the analogue input of the digital control system. FRF plots of the shaft strain gauge response with the armature current signal as reference were calculated at speeds of 250, 500, 750 and 1000 rpm (Table 2). The FRF plot for a rotor speed of $750 \mathrm{rpm}$ and with a blade stagger angle of $0^{\circ}$ is shown in Fig. 8. It should be noted that the natural frequencies for the dynamic case (i.e. motor field and control system active) for modes F2 and F3 reduce by approximately $4 \%$ and $5 \%$ respectively with respect to the static condition (i.e. with motor field and control system off). Modes F1 and F4 do not appear to be affected by this. This phenomenon is believed to be due to the electro-
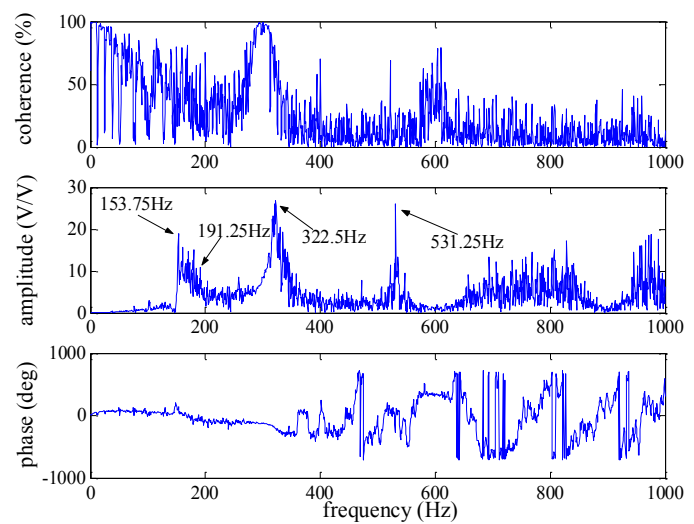

Fig. 8. FRF at $750 \mathrm{rpm}$ with stagger angle at $0^{\circ}$ with random excitation.
Table 2. Measured torsional frequencies for random excitation.

\begin{tabular}{|c|c|c|c|c|c|}
\hline $\begin{array}{l}\text { Blade } \\
\text { stagger } \\
\text { angle }\end{array}$ & $\begin{array}{l}\text { Speed } \\
(\mathrm{rpm})\end{array}$ & $\begin{array}{l}F_{1} \\
(\mathrm{~Hz})\end{array}$ & $\begin{array}{l}\mathrm{F}_{2} \\
(\mathrm{~Hz})\end{array}$ & $\begin{array}{l}\mathrm{F}_{3} \\
(\mathrm{~Hz})\end{array}$ & $\mathrm{F}_{4}(\mathrm{~Hz})$ \\
\hline \multirow{4}{*}{$0^{\circ}$} & 250 & 151.88 & 190.00 & 320.00 & 530.63 \\
\hline & 500 & 151.25 & 189.38 & 323.75 & 531.88 \\
\hline & 750 & 153.75 & 191.25 & 322.50 & 531.25 \\
\hline & 1000 & 153.75 & 188.75 & 322.50 & 532.50 \\
\hline \multirow{3}{*}{$45^{\circ}$} & 250 & 148.75 & 193.13 & 310.63 & 530.63 \\
\hline & 500 & 147.50 & 191.25 & 305.63 & 530.6 \\
\hline & 1000 & 148.75 & 191.50 & 302.50 & 530.00 \\
\hline \multirow{4}{*}{$90^{\circ}$} & 250 & & 188.75 & 293.13 & 530.63 \\
\hline & 500 & & 184.38 & 292.50 & 531.25 \\
\hline & 750 & & 187.50 & 293.13 & 530.00 \\
\hline & 1000 & & 186.25 & 291.25 & 530.00 \\
\hline
\end{tabular}

magnetic forces created in the DC motor, affecting the stiffness of the motor.

Similar to the static case, changes in blade orientation resulted in significant frequency changes in mode F3 but less so in mode F1. Modes F2 and F4 were not affected.

A second set of tests were done to confirm the results of the random excitation tests. Using a function generator, single short-duration square waves were generated and coupled to the analogue input of the control system for impulse torque loading of the rotor (Fig. 9). Tests were conducted at mean speeds of 250, 500, 750 and $940 \mathrm{rpm}$ with the blades at $0^{\circ}, 45^{\circ}$ and $90^{\circ}$. The results were similar to those obtained through random excitation. A slight speed dependency was noted only in mode F2 for a blade stagger angle of $45^{\circ}$, similar to the finding for random excitation (Fig. 10).

No significant centrifugal stiffening effect was measured in the speed range tested (up to $1000 \mathrm{rpm}$ ).

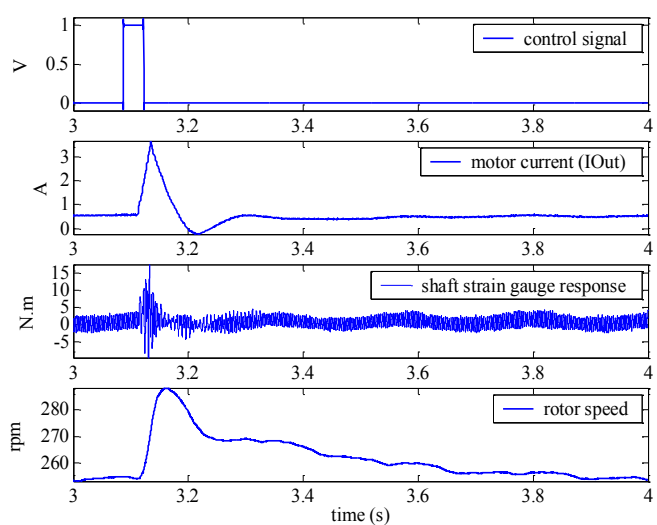

Fig. 9. Typical torque impulse loading and response with blades at $0^{\circ}$. 


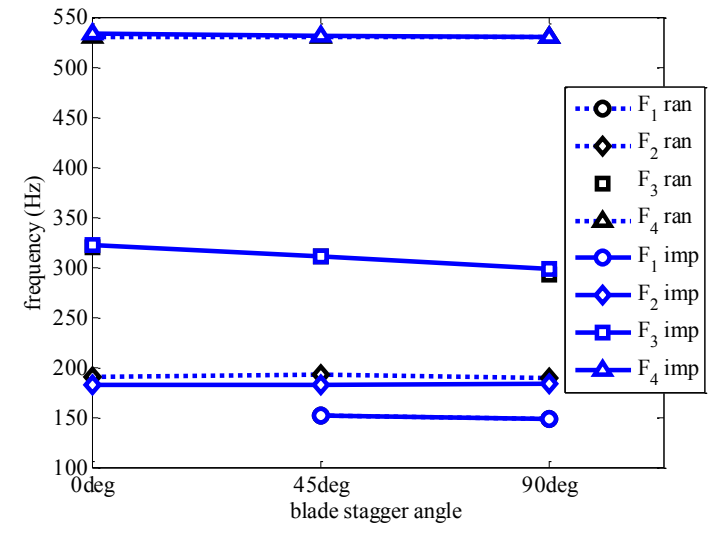

Fig. 10. Frequency change with blade stagger angle for random (ran) and impulse (imp) excitation at a mean speed of $250 \mathrm{rpm}$.

\section{Full 3-dimensional finite element analysis (3D FEA)}

The complete rotor with couplings, coupling bolts, blades, holders and disks was modelled in 3D and meshed, using the commercial software Ansys. Hexahedral elements were used for the shaft sections, blades and where practical. More complex geometries such as the disks, couplings and blade holders were meshed using tetrahedral elements. Both couplings were attached by bonded contact up to the points of effective contact. For the NDE coupling of disk \#3, this was taken as the length from the outboard face up to the centre of the NDE coupling grub screw. Effective contact for the DE coupling was taken as starting at the coupling key.

The shaft sections of the armature were modelled as steel sections with an elastic modulus and density of $207 \mathrm{GPa}$ and $7850 \mathrm{~kg} / \mathrm{m}^{3}$, the same as for all the other steel parts. For the larger diameter winding and commutator sections which have a complex construction of a steel base, copper windings and laminated plates, the density and stiffness were calibrated to represent the measured total armature polar moment of inertia and to minimize the difference between the calculated and measured frequencies.

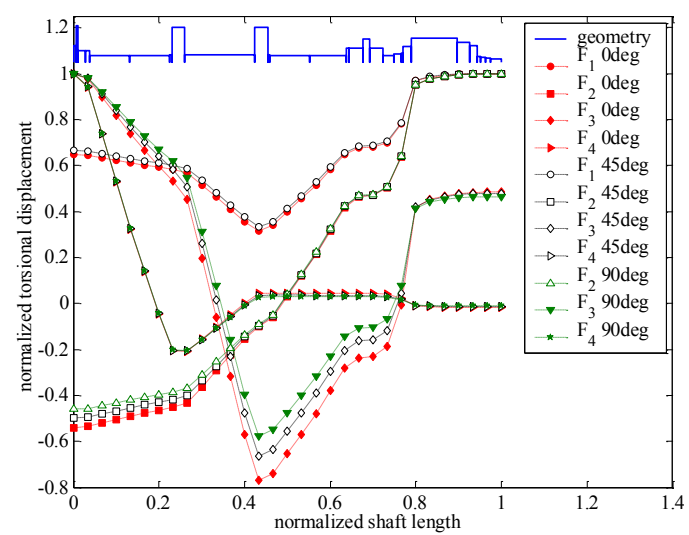

Fig. 11. Shaft mode shapes calculated by 3D FEA.
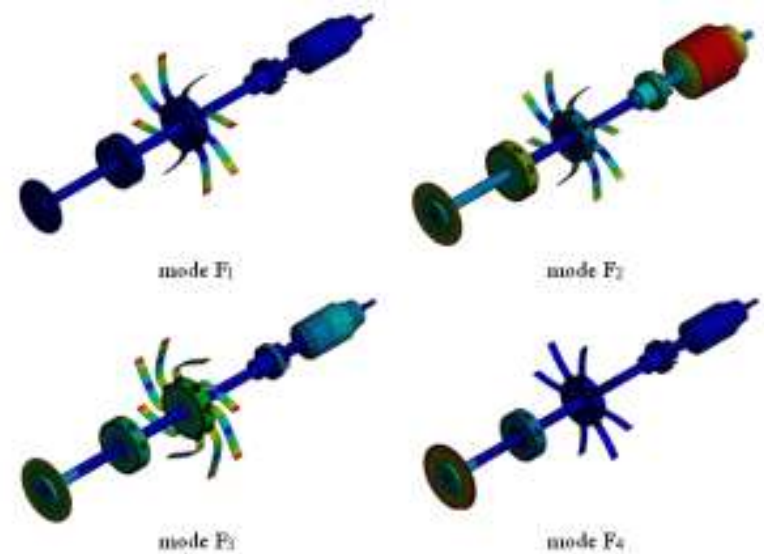

Fig. 12. 3D FEA mode shapes of the test rotor.

Coupled rotor frequencies for a range of densities and elastic moduli were calculated by 3D FEA and a composite error index was defined as the average of the absolute differences between the calculated and measured frequencies of modes F1 to F4. The meshing of the complete rotor model resulted in 71016 elements and 131282 nodes. A density of $3855.5 \mathrm{~kg} / \mathrm{m}^{3}$ was used to ensure that the modelled polar moment of inertia was equal to the measured value. Based on this density, the minimum error index occurs for an elastic modulus of 4.3 GPa.

Calculated shaft mode shapes are depicted in Fig. 11 and the 3D plots of the mode shapes are shown in Fig. 12. In all cases, the blade tip movement is out of phase with the rotor and the blade mode shape is the first bending mode.

In the 3D static case good correlation with the measured data was found (Table 3). The average solution time for the 3D static modal analyses was found to be 100s.

A pre-stress modal analysis of the rotor with the blades at $0^{\circ}, 45^{\circ}$ and $90^{\circ}$ was done for speeds ranging from 0 to 6000 $\mathrm{rpm}$. Although the maximum tested speed was only up to $1000 \mathrm{rpm}$ (for safety reasons), calculations were done up to the higher speed to show that some modes are affected by centrifugal stiffening (Fig. 13). The results of the analysis indicate that torsional frequencies are affected only by rotational speed from approximately $2000 \mathrm{rpm}$. Modes F2 and F4 do not appear to be affected by speed. A consistent non-linear speed dependency is seen for modes F1 and F2. The average solution time for pre-stressed modal analyses is $110 \mathrm{~s}$.

Table 3. 3D FEA error in static torsional frequencies relative to experimental results.

\begin{tabular}{c|c|c|c|c}
\hline $\begin{array}{c}\text { Blade } \\
\text { stagger angle }\end{array}$ & $\mathrm{F}_{1}(\%)$ & $\mathrm{F}_{2}(\%)$ & $\mathrm{F}_{3}(\%)$ & $\mathrm{F}_{4}(\%)$ \\
\hline $0^{\circ}$ & $-0.7 \%$ & $0.2 \%$ & $-0.6 \%$ & $0.0 \%$ \\
\hline $45^{\circ}$ & $-0.1 \%$ & $-0.5 \%$ & $0.2 \%$ & $0.1 \%$ \\
\hline $90^{\circ}$ & & $-0.7 \%$ & $-0.5 \%$ & $0.1 \%$ \\
\hline no blades & & $-0.9 \%$ & $-0.8 \%$ & $0.1 \%$ \\
\hline
\end{tabular}




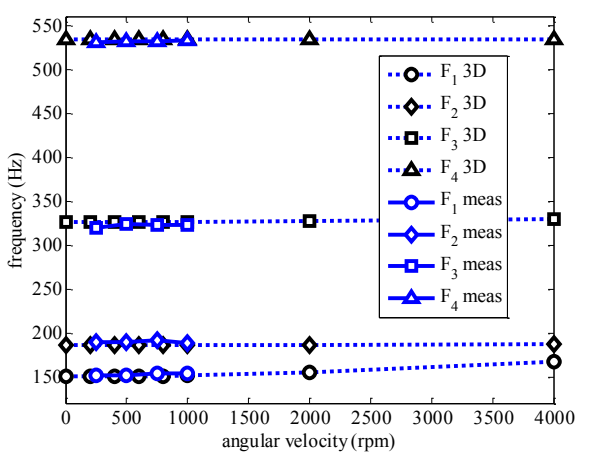

(a)

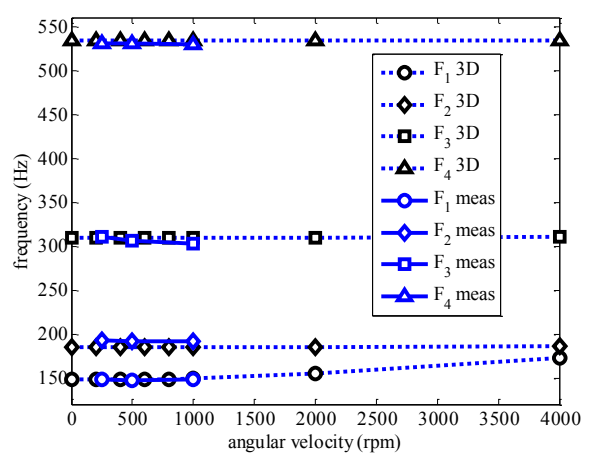

(b)

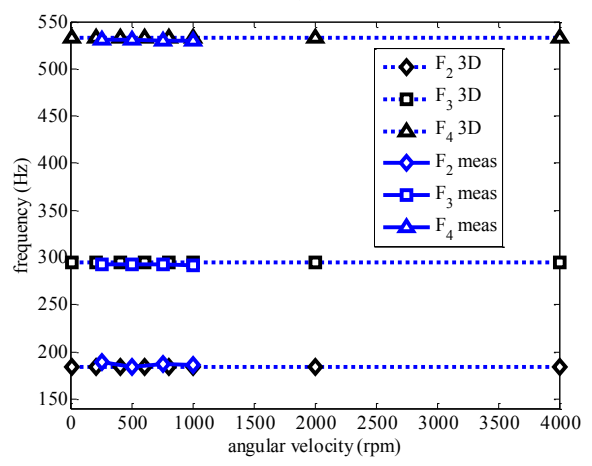

(c)

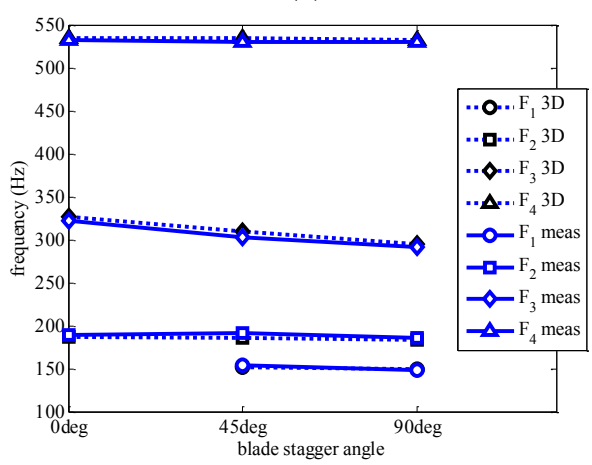

(d)

Fig. 13. Campbell diagrams for rotor with blade stagger angles of $0^{\circ}(\mathrm{a}), 45^{\circ}(\mathrm{b})$, and $90^{\circ}$ (c). Correlation between measured (meas) and 3D FEA (3D) calculations at $1000 \mathrm{rpm}(\mathrm{d})$.

\section{Three dimensional cyclic symmetric model (3DCS)}

A $45^{\circ}$ cyclic symmetrical model of the rotor was developed, maintaining all full 3D model geometry features and including one blade. Cyclic symmetrical faces were defined on both sides of the segment before meshing to the same level of refinement as for the full 3D models. A reduction of more than $80 \%$ in model size was achieved i.e. 10271 elements and 22401 nodes were defined. Bonded contact was used between the rotor and armature shafts and the couplings as was modelled in the full 3D case.

The properties of the material were kept the same as for the full 3D case, including the density and elastic modulus of the armature winding and commutator sections.

The calculated torsional frequencies were similar to those obtained by full 3D analysis (Table 4) but required significantly lower solution times i.e. $5 \mathrm{~s}$ for the static case and $22 \mathrm{~s}$ for the pre-stressed case, a reduction of $>80 \%$.

\section{One-dimensional FEA approach}

The conventional method used to determine torsional natural frequencies in bladed rotors is based on what is called the one-dimensional finite element approach. This approach requires a significant simplification of the geometry and other aspects such as sudden diameter changes, shrunk-on disks and flexible blades. Based on previous findings [15], disks were assumed to be integral with the shaft. Shaft sections were defined to include additional virtual shaft lengths due to sudden diameter changes, as well as taking into consideration the effective coupling contact lengths. The densities and elastic moduli for the various shaft, disk and motor winding sections were based on the same values as those used in the $3 \mathrm{D}$ models.

\subsection{Shaft sections and sudden diameter changes}

Shaft sections were modelled by using a distributed parameter approach and finite element discretization. To account for sudden changes in diameter, the approach of the British Internal Combustion Engine Research Association (BICERA) was applied. In this approach, a virtual shaft length $\left(L_{v}\right)$ is added to the shaft with the smaller diameter $\left(D_{l}\right)$ based on the ratio of the shaft diameters $\left(D_{2} / D_{1}\right)$ and the ratio of the fillet radius to the smaller shaft radius $\left(r / R_{l}\right)$. The solid markers in Fig. 14 are the discretized points obtained from an original BICERA graph provided in [16]. A third-order polynomial fitted to these points to obtain the data points shown by open

Table 4. 3DCS FEA error in static torsional frequencies relative to experimental results.

\begin{tabular}{c|c|c|c|c}
\hline $\begin{array}{c}\text { Blade } \\
\text { stagger angle }\end{array}$ & $\mathrm{F}_{1}(\%)$ & $\mathrm{F}_{2}(\%)$ & $\mathrm{F}_{3}(\%)$ & $\mathrm{F}_{4}(\%)$ \\
\hline $0^{\circ}$ & $-0.7 \%$ & $0.0 \%$ & $-0.6 \%$ & $0.0 \%$ \\
\hline $45^{\circ}$ & $0.0 \%$ & $-0.5 \%$ & $0.0 \%$ & $0.2 \%$ \\
\hline $90^{\circ}$ & & $-1.0 \%$ & $-0.7 \%$ & $0.2 \%$ \\
\hline no blades & & $-1.0 \%$ & $-1.1 \%$ & $0.2 \%$ \\
\hline
\end{tabular}




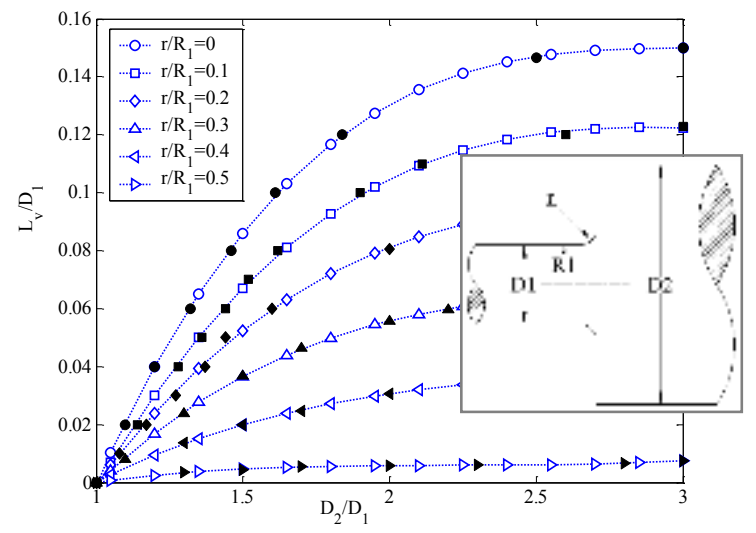

Fig. 14. BICERA compensation factors for sudden diameter change. NOTE: Solid markers are discretized points from the original graph and the open markers are fitted points.

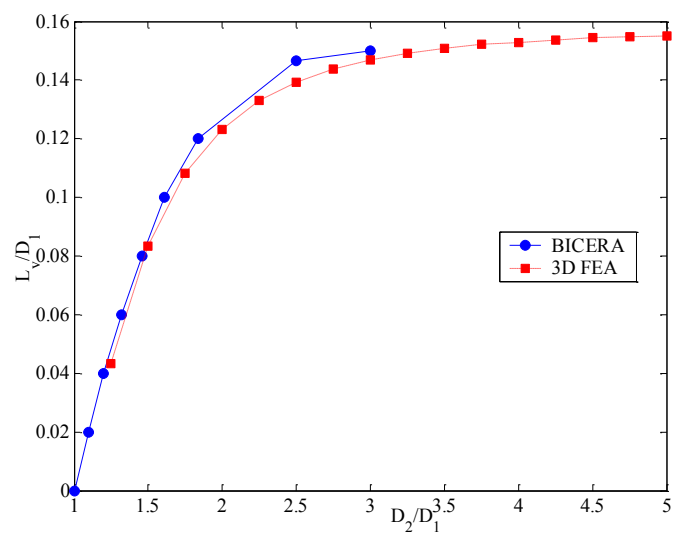

Fig. 15. 3D FEA extension of BICERA data for $r / R_{I}=0$.

markers. The BICERA data is however only provided up to a diameter ratio of 3 whereas the disk-to-shaft ratio for the test rotor approaches 5 .

3D FEA was used to extend the $r / R_{1}=0$ curve to a diameter ratio $\left(D_{2} / D_{l}\right)$ of 5 . Small differences between the BICERA and 3D FEA data were noted in the diameter ratio range of 2 to 3 (Fig. 15). This may be due to mesh refinement or other unknown geometric or measurement factors in the BICERA data. Nonetheless, the fit is considered acceptable for this approach.

\subsection{D Modelling of blades}

Euler-Bernoulli beam theory with finite element discretization was used for modelling the blades and for the component mode synthesis approach of coupling blade vibration modes to the rotor. Each element has two nodes, each with a translational and rotational degree of freedom. The elemental mass $[M]$ and stiffness $[K]$ matrices are shown below in equations Error! Reference source not found. and Error! Reference source not found. [17], where $m_{e}$ is the elemental mass, $L$ is the element length, $E$ is the elastic modulus and $I$ is the area moment of inertia.

The attachment DOFs, $x_{s a}$ and $\theta_{s a}$ are assumed to be fixed for the calculation of the internal modes of a blade (Fig. 16). Equations of motion are solved to obtain the eigenvectors and eigenfrequencies of the blade substructure from equation (3).

The resultant eigenvector matrix $\Phi$ is an $n$ by $g$ matrix, where $n$ is the number of DOFs of the blade substructure and $g$ is the number of blade modes used to synthesize the component mode/s.

The transformation matrix, $\boldsymbol{W}_{i}$ which was used to transform the mass and stiffness constraint mode matrices (attachment DOF included) from the absolute to the modal coordinate system is of the form as presented in equation (4).

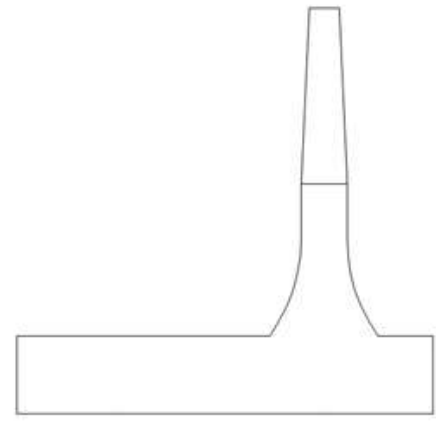

(a) Actual shaft-disc-blade system.

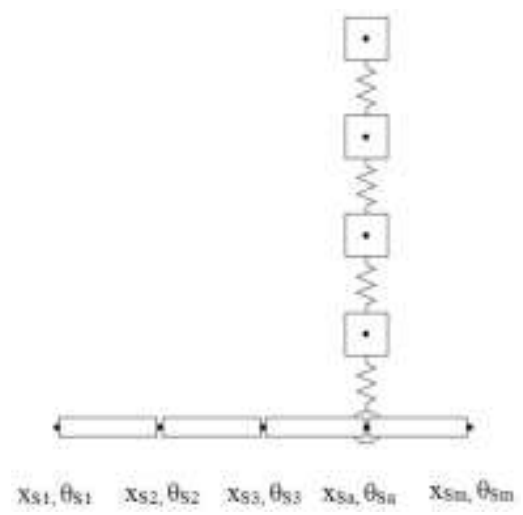

(b) Discretized model.

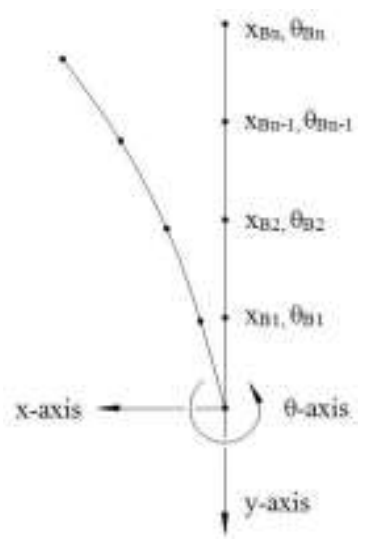

(c) Coordinate system for model. 
Fig. 16. Discretization of shaft-disk-blade system

$[M]=\frac{m_{e}}{420}\left[\begin{array}{cccc}156 & 22 L & 54 & 13 L \\ 22 L & 4 L^{2} & 13 L & -3 L^{2} \\ 54 & 13 L & 156 & -22 L \\ -13 L & -13 L^{2} & -22 L & 4 L^{2}\end{array}\right](1)$

$[K]=\left[\begin{array}{cccc}\frac{12 E I}{L^{3}} & \frac{6 E I}{L^{2}} & -\frac{12 E I}{L^{3}} & \frac{6 E I}{L^{2}} \\ \frac{6 E I}{L^{2}} & \frac{4 E I}{L} & \frac{-6 E I}{L^{2}} & \frac{2 E I}{L} \\ \frac{-12 E I}{L^{3}} & \frac{-6 E I}{L^{2}} & \frac{12 E I}{L^{3}} & \frac{-6 E I}{L^{2}} \\ \frac{6 E I}{L^{2}} & \frac{2 E I}{L} & \frac{-6 E I}{L^{2}} & \frac{4 E I}{L}\end{array}\right]$

$\left[M_{B}\right]\left\{\begin{array}{c}\ddot{x}_{B 1} \\ \ddot{\theta}_{B 1} \\ \vdots \\ \ddot{x}_{B n} \\ \ddot{\theta}_{B n}\end{array}\right\}+\left[K_{B}\right]\left\{\begin{array}{c}x_{B 1} \\ \theta_{B 1} \\ \vdots \\ x_{B n} \\ \theta_{B n}\end{array}\right\}=0$

$\left[W_{j}\right]=\left[\begin{array}{ll}I & 0 \\ \psi & \phi_{j}\end{array}\right]$

the modal to the absolute coordinate system. Let $\theta_{R l}^{*}$ be the DOF to which the equivalent blade mode will be attached:

$$
\begin{aligned}
& \theta_{B 1}^{*}=\theta_{s a}+f(\alpha) \\
& {\left[\begin{array}{c}
x_{s a} \\
\theta_{s a} \\
\alpha
\end{array}\right]=\xi\left[\begin{array}{c}
x_{s a} \\
\theta_{s a} \\
\theta_{B 1}^{*}
\end{array}\right]} \\
& \xi=\left[\begin{array}{ccc}
1 & 0 & 0 \\
0 & 1 & 0 \\
0 & -y & y
\end{array}\right]
\end{aligned}
$$

$\Phi_{i}$ is the eigenvector of mode $i$ to be transformed and $\psi$ is a vector describing the displacements of the internal DOFs of the substructure for a unit displacement of the attachment DOF. In this case all the blade DOFs, $x_{B n}$ and $\theta_{B n}$ have to be written in terms of the rotor angular DOF, $\theta_{s a}$, located at the centreline of the shaft by:

$$
\begin{aligned}
& x_{B n}=x_{s a}+R_{B n} \theta_{s a}+\phi_{x j n} \alpha \\
& \theta_{B n}=\theta_{s a}+\phi_{\theta j n} \alpha
\end{aligned}
$$

where $R_{B n}$ is the radial distance of node $n$ from the shaft centreline and $\alpha$ is a modal scaling factor. The modal mass $(M r j)$, and stiffness $\left(K_{r j}\right)$ matrices for a single transformed mode $j$ are obtained from the blade substructure mass and stiffness matrices $\left[M_{B C}\right]$ and $\left[K_{B C}\right]$ by $[18]$ :

$$
\begin{aligned}
& \mathbf{W}_{j}^{T} \mathbf{M}_{B C} \mathbf{W}_{j}=M_{r j} \\
& \mathbf{W}_{j}^{T} \mathbf{K}_{B C} \mathbf{W}_{j}=K_{r j}
\end{aligned}
$$

Setting $y$ equal to the ratio of $m_{c \theta}$ and $m_{r j}$ and applying the transformation to $\boldsymbol{M}_{r j}$ the following is obtained when the translation DOF is also ignored [19]:

$$
\xi M_{r j} \xi=\left[\begin{array}{cc}
m_{t \theta}-y^{2} m_{r j} & 0 \\
0 & y^{2} m_{r j}
\end{array}\right]
$$

where $\mathrm{y}^{2} \mathrm{~m}_{\mathrm{rj}}$ is the equivalent blade inertia $\left(m_{e q}\right)$ and $m_{t \theta^{-}} y^{2} m_{r j}$ is the residual blade inertia $(\Delta m)$

The same process is conducted for each blade mode and the equivalent mode/s inertia and stiffness are attached to the relevant torsional system DOF. The total residual inertia is added to the torsional system DOF inertia to which the mode/s are connected. Multiple blades are accounted for by neglecting the "rigid" shaft modes, i.e. assuming that blades are tuned and respond in phase with one another. The blade stagger angle $(\beta)$ is accounted for in the torsional analysis by coupling only the tangential components of the eigenvector using the blade substructure mass matrix with attachment DOFs fixed $\left(M_{B}\right)$ as follows:

$$
m_{c \theta j}=\psi^{T} M_{B} \phi_{t j}
$$




$$
\phi_{t j}=\phi_{j} \cos \beta
$$

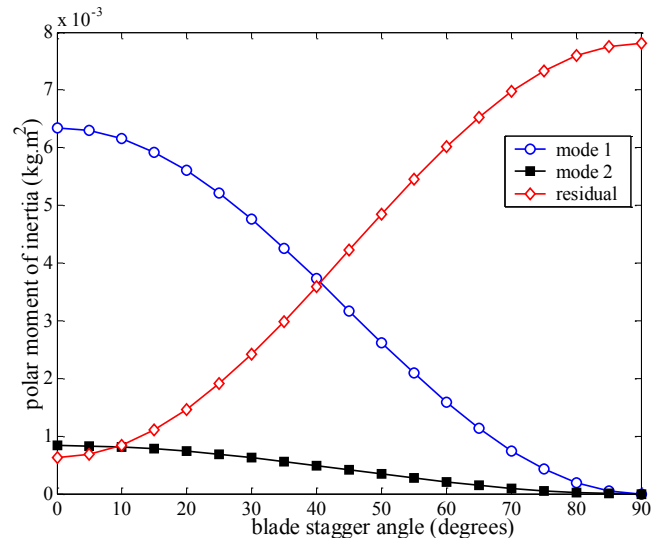

Fig. 17. Equivalent inertia for coupled blade modes.

The first two blade modes were coupled and the variation of the equivalent inertias and the residual inertia with blade stagger angle are presented in Fig. 17. The equivalent inertia contribution from the first bending mode is significantly more than that for the second bending mode. As expected, the equivalent tangential inertias for an orientation angle of $90^{\circ}$ is zero as there is no blade participation in this case.

\subsection{Qualitative representation of blade participation}

Small equivalent inertias are calculated in cases where a blade vibration mode couples lightly with a shaft torsional mode. Moreover, due to numerical errors, very small inertias and stiffness values can be calculated in cases where no coupling should exist. In these cases the resultant relative displacement of these blade mode DOFs can be very large and a simple plot of the eigenvector will not be representative of the level of blade mode participation. It is proposed that the level of participation of a blade equivalent inertia at DOF $i$ for eigenmode $j$ should be represented on the basis of the relative momentum $P i j$ of the vibrating DOF as follows:

$$
\begin{aligned}
\gamma_{i j} & =\frac{\left|P_{i j}\right|}{\sum_{i=1}^{i=n}\left|P_{i j}\right|} \\
P_{i j} & =J_{i} \theta_{i j} F_{j}
\end{aligned}
$$

where $n$ is the total number of DOF, $J_{i}$ is the inertia in DOF $i$. $\theta_{i j}$ is the torsional displacement if DOF $i$ for mode $j$ and $F_{j}$ is the frequency of mode $j$. The blade participation factor, $\gamma_{i j}$, is then used to scale the blade mode DOF in the normalized eigenvector.

\subsection{Calculated results}

The calculated frequencies (Table 5) for the cases investigated correlate well with the experimental results (Table 6) as well as with the 3D FEA results (Table 7). Frequency change with blade stagger angle is shown in Fig. 18. Mode shape diagrams for the investigated cases are shown in Fig. 19. The relative participation levels of the blade modes $B_{1}$ and $B_{2}\left(1^{\text {st }}\right.$ and $2^{\text {nd }}$ bending) in the shaft modes are indicated by the dark vertical lines at the disk \#1 position. These lines may extend above or below the shaft mode-shape lines and represent modes $\mathrm{B}_{1}$ and $\mathrm{B}_{2}$ respectively. The length of the line/s from the attachment node (disk \#1) is an indication of the level of blade participation.

The solution times for the $1 \mathrm{D}$ static modal analyses were found to be in the order of 0.3 seconds.

Table 5. Calculated frequencies for rotor using 1D approach.

\begin{tabular}{ccccc}
\hline $\begin{array}{c}\text { Blade } \\
\text { stagger angle }\end{array}$ & $\mathrm{F}_{1}(\mathrm{~Hz})$ & $\mathrm{F}_{2}(\mathrm{~Hz})$ & $\mathrm{F}_{3}(\mathrm{~Hz})$ & $\mathrm{F}_{4}(\mathrm{~Hz})$ \\
\hline no blades & & 197.4 & 347.5 & 534.9 \\
$0^{\circ}$ & 151.4 & 197.6 & 333.3 & 534.1 \\
$45^{\circ}$ & 148.4 & 197.2 & 315.3 & 533.6 \\
$90^{\circ}$ & & 196.8 & 301.3 & 533.3
\end{tabular}

Table 6. Error in 1D model frequencies relative to experimental results.

\begin{tabular}{cllll}
\hline $\begin{array}{c}\text { Blade } \\
\text { stagger angle }\end{array}$ & $\mathrm{F}_{1}(\%)$ & $\mathrm{F}_{2}(\%)$ & $\mathrm{F}_{3}(\%)$ & $\mathrm{F}_{4}(\%)$ \\
\hline no blades & & $-1.3 \%$ & $-1.0 \%$ & $0.2 \%$ \\
$0^{\circ}$ & $-0.4 \%$ & $-0.2 \%$ & $-0.8 \%$ & $0.0 \%$ \\
$45^{\circ}$ & $-0.4 \%$ & $-0.9 \%$ & $0.1 \%$ & $0.1 \%$ \\
$90^{\circ}$ & & $-1.1 \%$ & $-0.6 \%$ & $0.0 \%$
\end{tabular}

Table 7. Error in 1D model frequencies relative to 3D FEA results.

\begin{tabular}{cllll}
\hline $\begin{array}{c}\text { Blade } \\
\text { stagger angle }\end{array}$ & $\mathrm{F}_{1}(\%)$ & $\mathrm{F}_{2}(\%)$ & $\mathrm{F}_{3}(\%)$ & $\mathrm{F}_{4}(\%)$ \\
\hline no blades & & $-0.3 \%$ & $-0.1 \%$ & $0.0 \%$ \\
$0^{\circ}$ & $0.2 \%$ & $-0.2 \%$ & $-0.2 \%$ & $0.0 \%$ \\
$45^{\circ}$ & $-0.4 \%$ & $-0.4 \%$ & $-0.2 \%$ & $-0.1 \%$ \\
$90^{\circ}$ & & $-0.6 \%$ & $0.1 \%$ & $0.0 \%$
\end{tabular}

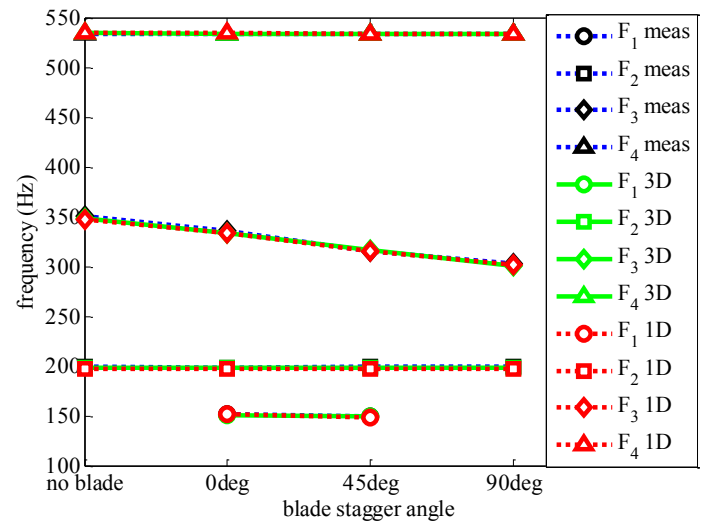

Fig. 18. Frequency reduction vs. blade stagger angle for static conditions. 
Fig. 19. Mode-shapes of rotor using 1D analysis
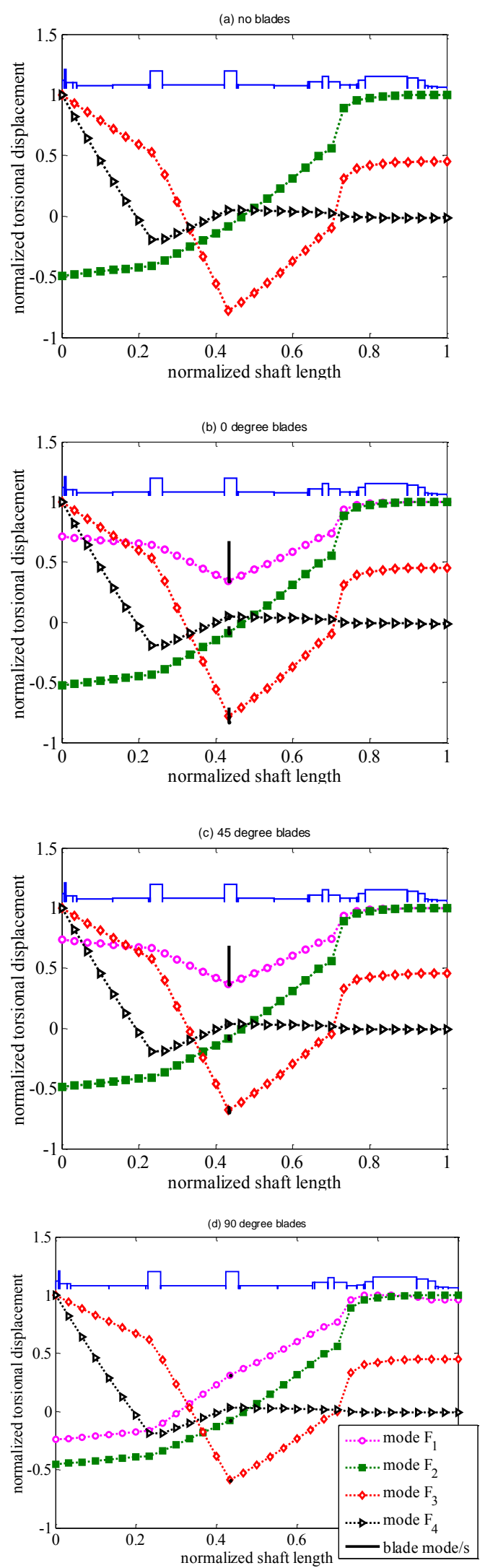

\section{Conclusions}

The drive and torsional excitation of small-scale test rotors can be successfully conducted using a DC motor and digital control system. The characterization of the drive system is essential to determine its torsional vibration response and the possible effects of such a response on rotor tests. Confidence in the accuracy and repeatability of measured vibration frequencies can be gained by measuring the response to multiple excitation types. The activation of electro-magnetic fields causes a shift in torsional frequencies. This requires dynamic testing to ensure that all relevant aspects affecting torsional vibration behaviour are captured. The damping of rotor torsional modes is affected by blade stagger and by rotational speed. Torsional frequencies are also affected by the blade stagger angle as well as high rotational speeds.

Torsional frequencies calculated with full 3D models with a high degree of geometric detail agree well with the measured results for static and dynamic conditions. The 3DCS models, obtained by simplifying the full 3D models, result in similar accuracy (Fig. 20) but have lower solution times. The visualization of torsional modes is enhanced by 3D modelling which also includes rigid shaft modes not available in the 1D approach.

Further reduction to 1D models requires a number of simplifications which result in smaller models with low solution times but also have a generally reduced accuracy. Blade torsional participation can be accomplished in the 1D approach using Euler-Bernoulli beam theory and the component mode synthesis technique.

It is concluded that all three of the FE techniques employed in this study are useful, depending on the required accuracy, and the available information and resources. In cases where a high level of accuracy is required, direct field measurements should be used for calibrating or updating the model. 

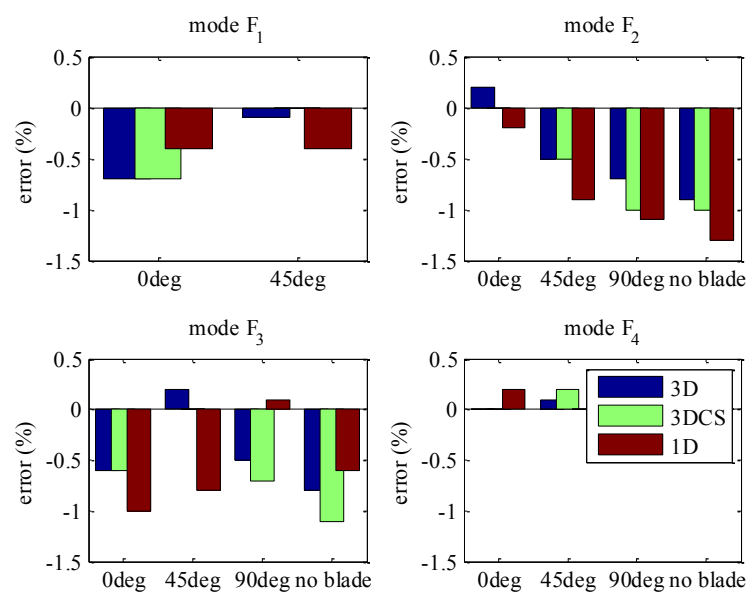

Fig. 20. FE model errors relative to experimental results.

\section{Acknowledgements}

The authors gratefully acknowledge support from the Eskom Power Plant Engineering Institute (EPPEI) as well as the NRF Technology and Human Resources Programme (THRIP).

\section{References}

[1] Q. Jiang, S. Cheng, and Y. Cao, "Lyapunov stability analysis of turbine-generator including shaft system," Electr. Power Energy Syst., vol. 25, pp. 741-746, 2003.

[2] J. Tsai, C. Lin, and T. Tsao, "Assessment of Long-Term Life Expenditure for Steam Turbine Shafts Due to Noncharacteristic Subharmonic Currents in Asynchronous Links," IEEE Trans. Power Syst., vol. 19, no. 1, pp. 507-516, 2004.

[3] EPRI, "Steam Turbine-Generator Torsional Vibration Interaction with the Electrical Network," 2005 .

[4] W. Tsai, "Improvement in the corrosive fatigue damage to the low-pressure steam turbine blades due to unbalanced currents," vol. 59, pp. 139$148,2001$.

[5] H. Nelson, "Rotordynamic Modeling and Analysis Procedures: A Review," Japan Soc. Mech. Eng. Int. J., vol. 41, no. C, pp. 1-12, 1998.

[6] T. Szolc, "On the Discrete-Continuous Modeling of Rotor Systems the Analysis of Coupled Lateral Torsional Vibrations," Int. J. Rotating Mach., vol. 6, no. 2, pp. 135-149, 2000.
G. Genta, "Present and future trends in rotordynamic analysis," 9th Int. Conf. Vib. Rotating Mach., 2008.

[8] A. Okabe, T. Kudo, K. Shiohata, O. Matsushita, H. Fujiwara, H. Yoda, and S. Sakurai, "Reduced Modeling for Turbine Rotor-Blade Coupled Bending Vibration Analysis," J. Eng. Gas Turbines Power, vol. 134, no. February, pp. 1-8, 2012.

[9] E. Chatelet, F. D'Ambrosio, and G. JacquetRichardet, "Toward global modelling approaches for dynamic analyses of rotating assemblies of turbomachines," J. Sound Vib., vol. 282, pp. 163-178, 2005.

[10] S. Drew and B. Stone, "Torsional (rotational) vibration: Excitation of small rotating machines.," J. Sound Vib., vol. 201, no. 4, pp. 437463, 1997.

[11] Y. Kim, B. Yang, and C. Kim, "Noise Source Identification of Small Fan-BLDC Motor System for Refrigerators," Int. J. Rotating Mach., vol. 2006, pp. 1-7, 2006.

[12] J. H. Leong and Z. Q. Zhu, "A Novel Torsional Excitation Scheme for Determining Mechanical Transfer Function and Natural Frequencies of Circumferential Vibration in PM Brushless Machine Drives," vol. 47, no. 10, pp. 4195-4198, 2011.

[13] O. Turhan, G. Bulut, and A. I. N. Press, "Linearly coupled shaft-torsional and blade-bending vibrations in multi-stage rotor-blade systems," J. Sound Vib., vol. 296, pp. 292-318, 2006.

[14] G. Jacquet-Richardet, G. Ferraris, P. Rieutord, L. De Me, A. A. Einstein, and V. Cedex, "Frequencies and modes of rotating flexible bladed discshaft assemblies: A global cyclic symmetric approach,” J. Sound Vib., vol. 191, no. 5, pp. 901915, 1996.

[15] J. M. Vance, B. T. Murphy, and H. A. Tripp, "Critical Speeds of Turbomachinery: Computer Predictions vs . Experimental Measurements Part I: The Rotor Mass - Elastic Model," J. Vib. Acoust. Stress Reliab. Des., vol. 109, no. January, pp. 1-7, 1987.

[16] D. N. Walker, Torsional Vibration of Turbomachinery. 2009. 
[17] B. Al-Bedoor, "Dynamic model of coupled shaft torsional and blade bending deformations in rotors," Comput. Methods Appl. Mech. Eng., vol. 5, no. 169, pp. 177-190, 1999.

[18] R. Cook, D. Malkus, M. Plesha, and R. Witt, Concepts and Applications of Finite Element Analysis, 4th ed. United States: John Wiley \& Sons, 2002.

[19] A. Okabe, H. Yoda, O. Matsushita, T. Kudo, S. Sakurai, K. Shiohata, and S. Sakuri, "Rotor Blade Coupled Vibration Analysis by measuring Modal Parameters of Actual Rotor," in ASME Turbo Expo 2009:Power for land, sea and air, 2009, pp. 803-812.

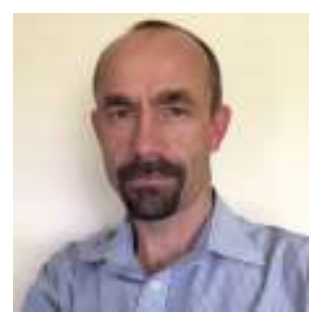

Ronnie Scheepers received his degree in mechanical engineering (BEng) at the University of Johannesburg in 1994 and his masters degree in mechanical engineering at the University of Pretoria in 2014 (cum Laude). He has 20 years of experience in the power generation field and is currently a corporate specialist with a power utility. His fields of interest include steam turbine blade vibration response, turbine life management and structural integrity.

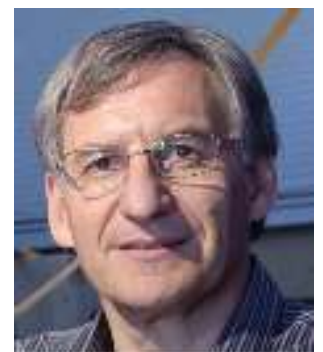

Stephan Heyns received his BSc degree in mechanical engineering in 1978 (cum Laude) and his PhD in 1988 from the University of Pretoria in South Africa. In 1982 he joined the Department of Mechanical and Aeronautical Engineering at the University of Pretoria. Presently he is Director of the Centre for Asset Integrity Management at the University of Pretoria as well as head of the Sasol Laboratory for Structural Mechanics. His current research interests are focused on machine and structural health diagnostics and prognostics, vibration analysis, vibration measurement techniques and structural integrity management. 